\title{
28 Research Square \\ Performance of wide band gap amorphous silicon alloys as passivation layer in graded band gap solar structure
}

\author{
Fatima Rasheed J ( $\sim$ fatimarasheed@cet.ac.in ) \\ College of Engineering Trivandrum https://orcid.org/0000-0002-1548-4699 \\ V.Suresh Babu \\ Government Engineering College Wayanad
}

\section{Research Article}

Keywords: wide band gap alloys, amorphous silicon nitride, amorphous silicon carbide, passivation layer, mole fraction, conversion efficiency

Posted Date: February 12th, 2021

DOI: https://doi.org/10.21203/rs.3.rs-221530/v1

License: (c) (i) This work is licensed under a Creative Commons Attribution 4.0 International License.

Read Full License 


\section{Abstract}

This work investigates the behaviour of two amorphous silicon wide band gap alloys: amorphous silicon nitride $(\mathrm{aSiN} x)$ and hydrogenated amorphous silicon carbide (aSi x C 1-x :H) as passivation layer in previously designed band gap tailored single junction photovoltaic structure: $\mathrm{p}+\mathrm{aSi}$ x C 1-x :H/i-aSi:H/n + aSi 1-x Gex :H. The work involves fabrication of PECVD made aSiN $x$ samples followed by detailed optical characterisation on band gap tailoring interms of mole fraction, $x$. A rigorous study is made on the current density-voltage $(\mathrm{J}-\mathrm{V})$ characteristics as well as on the Internal Quantum Efficiency (IQE) characteristics of the recommended band gap tailored solar structure using aSiN $\mathrm{x}$ and aSi x C 1-x : $\mathrm{H}$ as passivation layers. The progressive band gap tailored solar cell structure using aSi $\times \mathrm{C} 1-\mathrm{x}: \mathrm{H}$ passivation layer accomplishes conversion efficiency of $15.59 \%$ while similar structure having aSiN x passivation layer delivers an efficiency of $15.32 \%$. By virtue of the obtained results, it is observed that aSi x C 1-x :H with high carbon content is more efficient than aSiN $x$ to be considered as passivation layer. The work presents the performance of continuously band gap graded amorphous silicon alloy as passivation layer in single junction photovoltaic structures for the first time.

\section{Full Text}

Due to technical limitations, full-text HTML conversion of this manuscript could not be completed. However, the manuscript can be downloaded and accessed as a PDF.

\section{Figures}




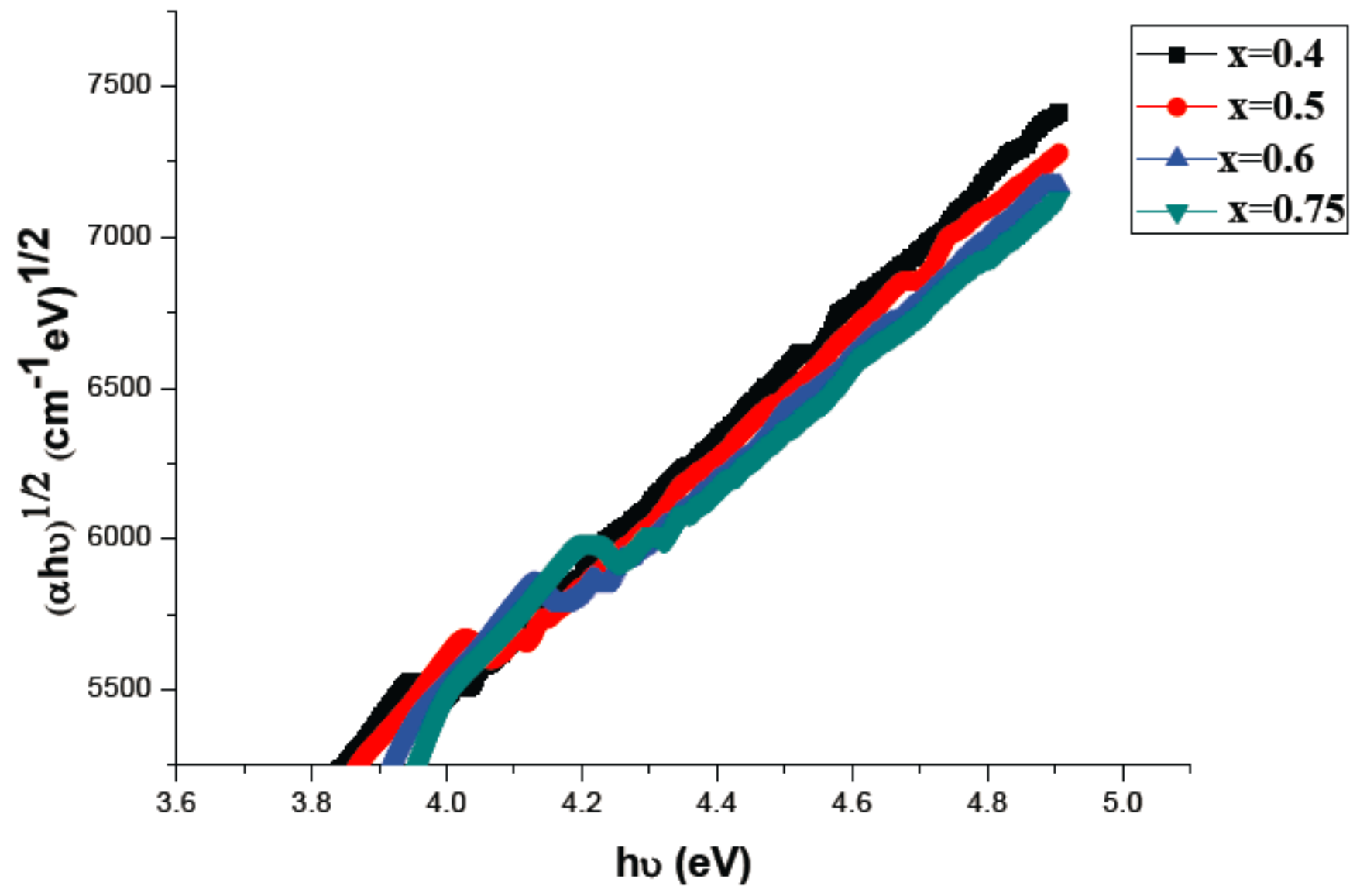

Figure 1

Tauc's plot obtained for different fabricated samples of aSiNx with varying mole fraction, $x$

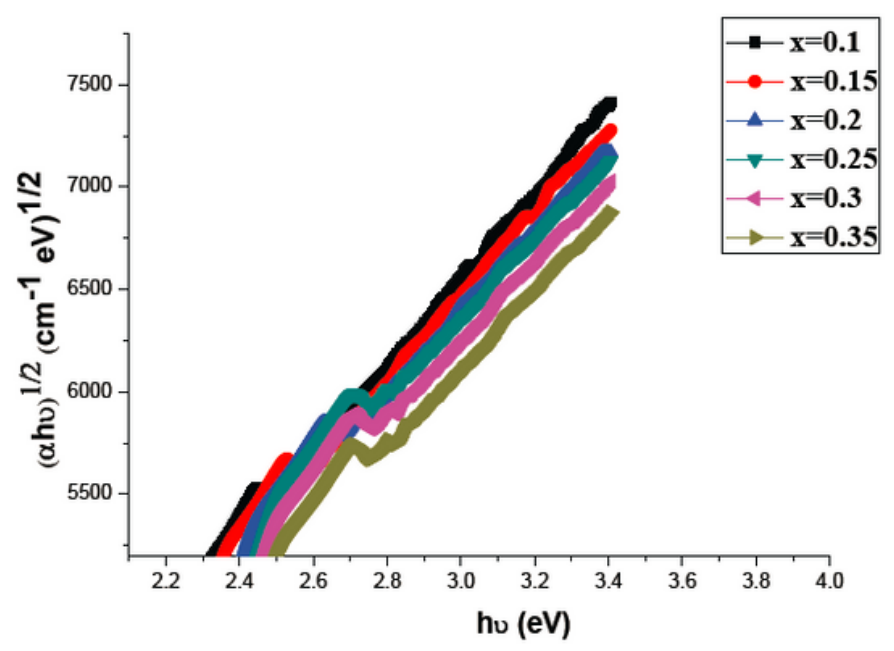

(a)

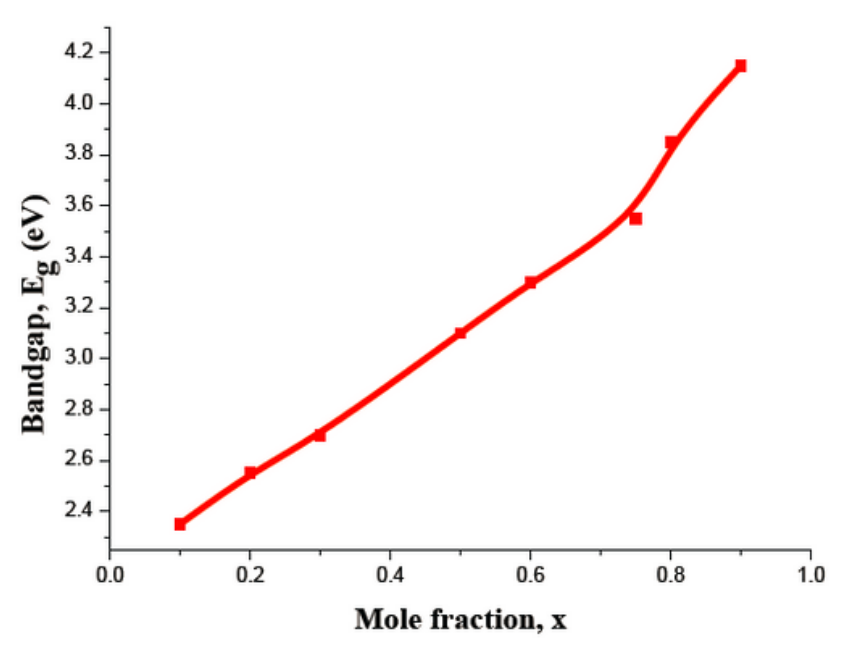

(b)

Figure 2 
(a) Investigations made on the basis of optical characterisation of the fabricated aSixC1-x:H films with varying mole fractions, $x$ done by Ambrosone et al. [10] (b) Findings on dependence of mole fraction on band gap of aSixC1-x:H films based on the experiments made by Lukianov et al. [11] and Tabata et al.[12]

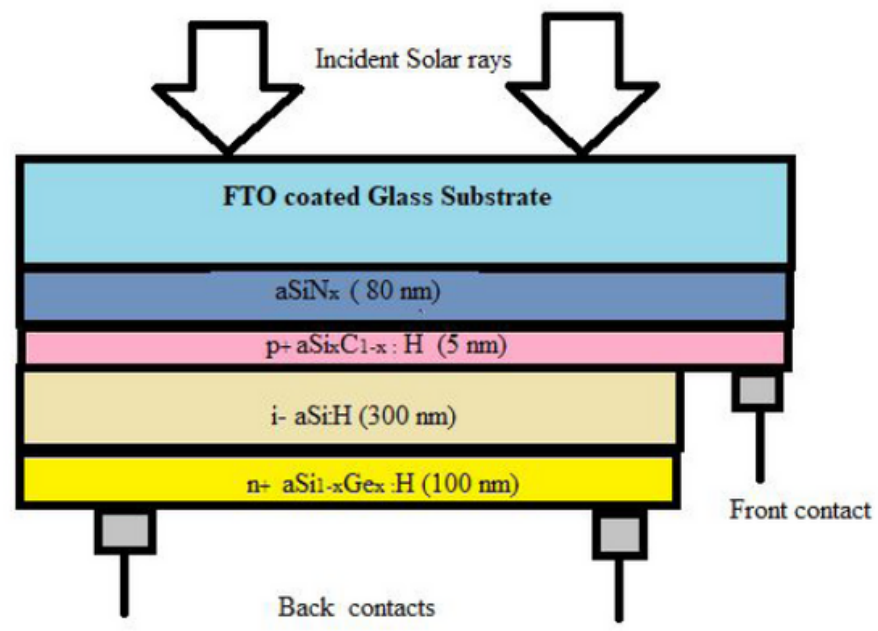

(a)

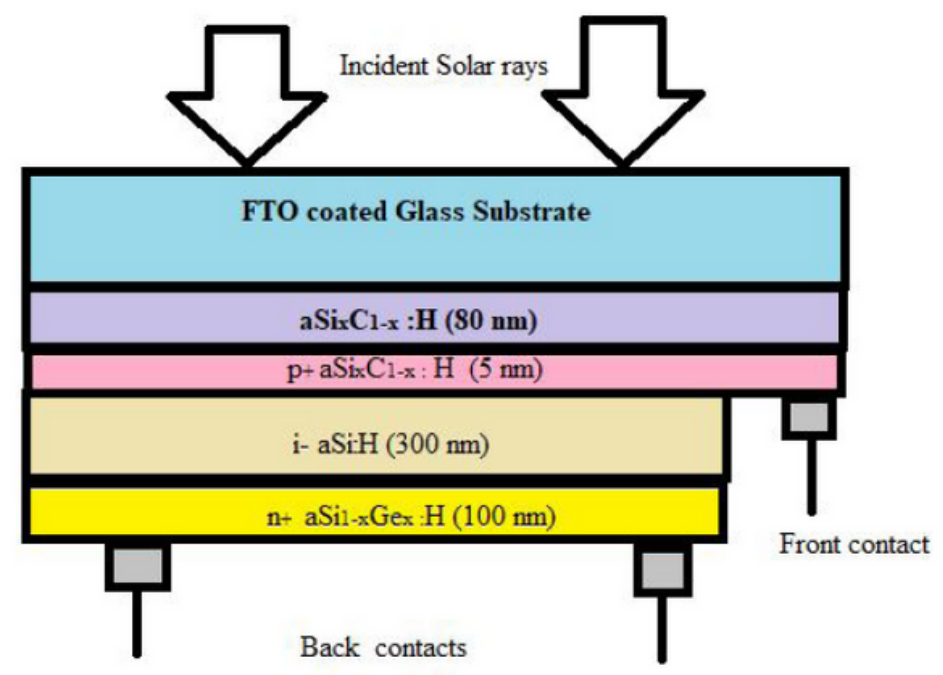

(b)

\section{Figure 3}

Proposed $\mathrm{p}+\mathrm{aSixC1}-\mathrm{x}: \mathrm{H} / \mathrm{i}-\mathrm{aSi}: \mathrm{H} / \mathrm{n}+\mathrm{aSi1}-\mathrm{xGex}: \mathrm{H}$ graded band gap single junction solar cell structure using (a) aSiNx as passivation layer (b) aSixC1-x:H as passivation layer

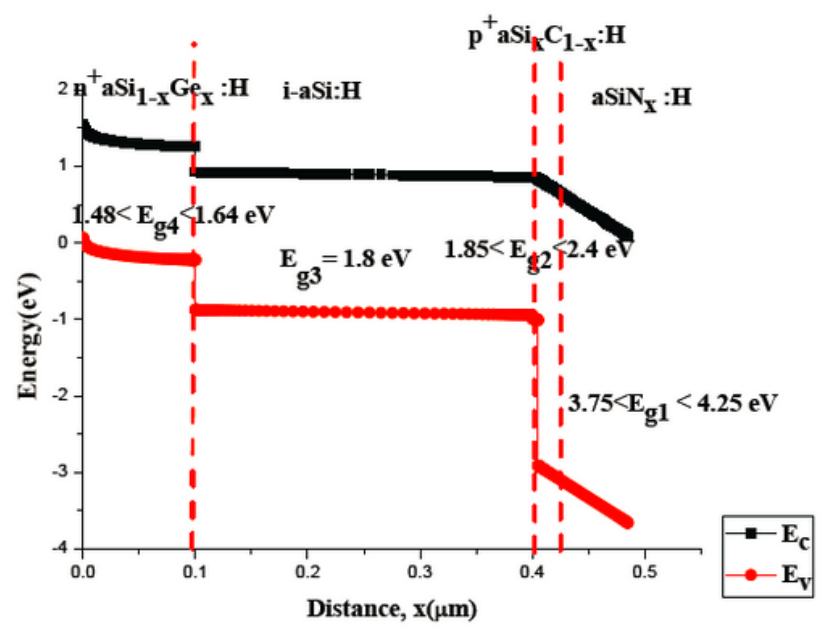

(a)

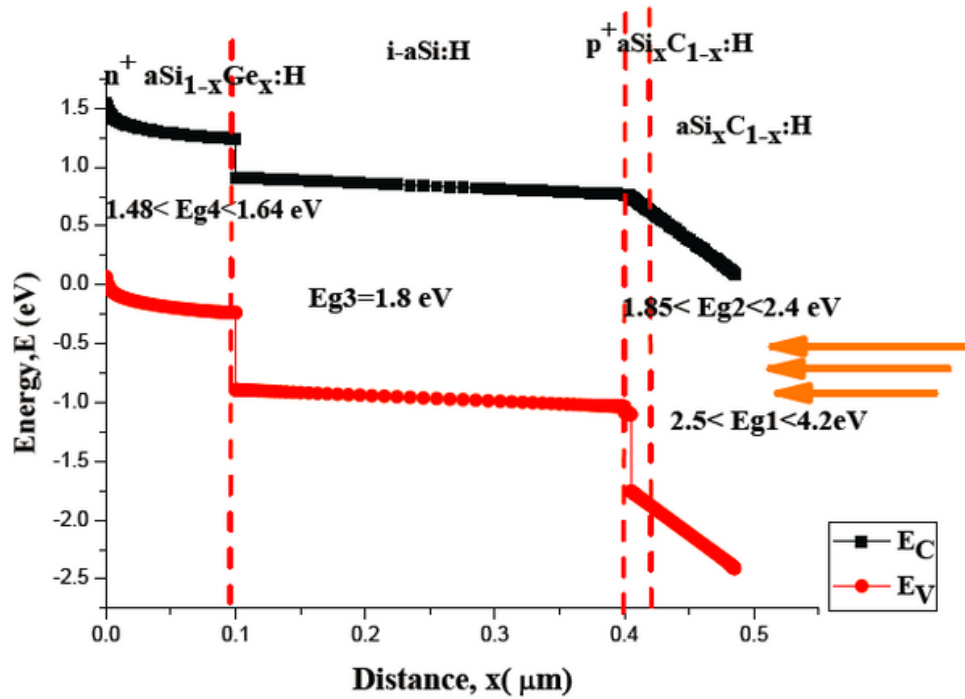

(b)

\section{Figure 4}

Energy band diagram of proposed p+aSixC1-x:H/i-aSi:H/n+aSi1-xGex:H graded band gap single junction solar cell structure using (a) aSiNx as passivation layer (b) aSixC1-x:H as passivation layer 


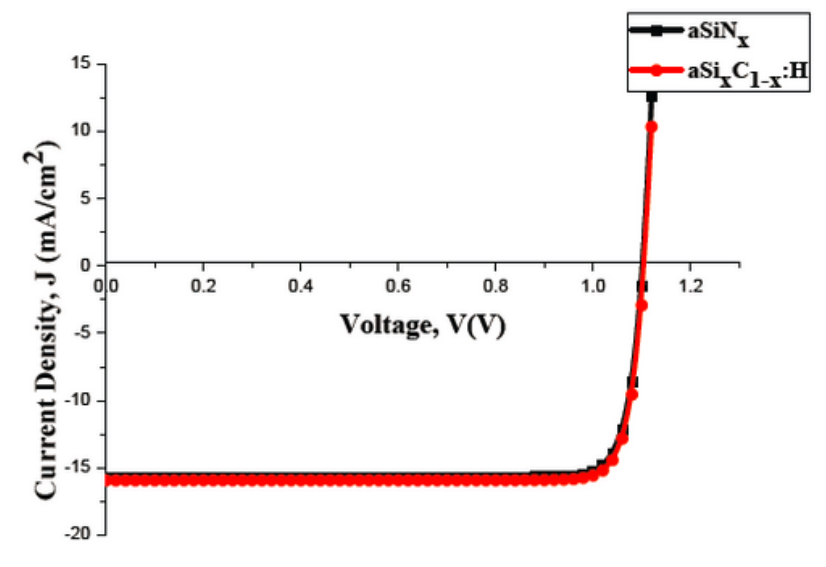

(a)

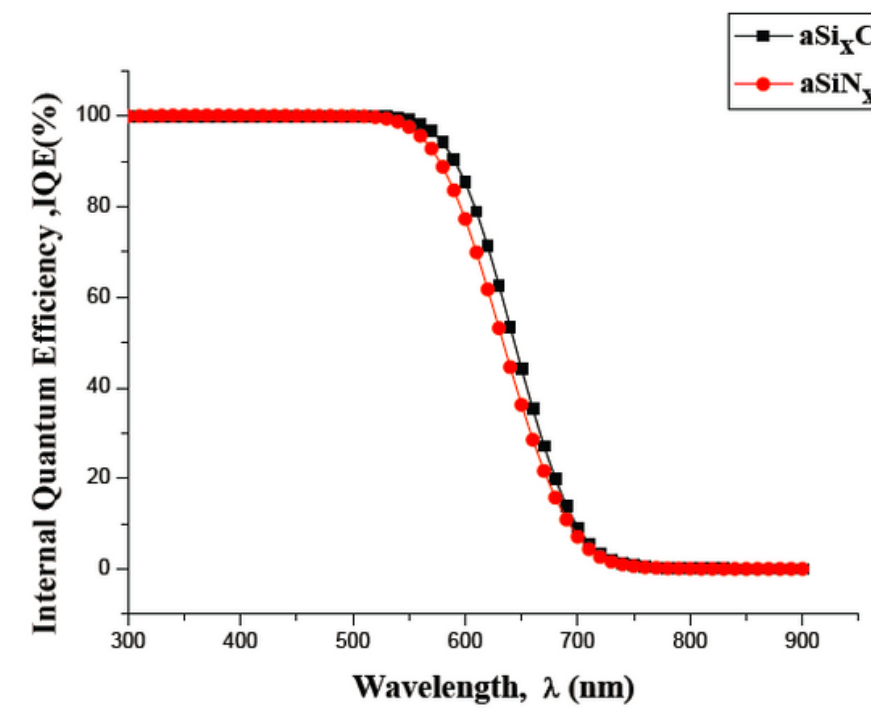

(b)

\section{Figure 5}

Comparison of of proposed p+aSixC1-x:H/i-aSi:H/n+aSi1-xGex:H graded band gap single junction solar cell structure using aSiNx and aSixC1-x:H as passivation layers (a) J-V characteristics (b) IQE characteristics 